\title{
Kısıtlar Teorisinde Kapasite Kısıtı ve Bir Üretim İşletmesinde Uygulaması
}

\author{
Cem Akçimen ${ }^{1 *}$, Figen Antmen ${ }^{1}$ \\ ${ }^{1}$ Çukurova Üniversitesi, Mühendislik Fakültesi, Endüstri Mühendisliği Bölümü, Adana, Türkiye (ORCID: 0000-0001-8475-1300)
}

(İlk Geliş Tarihi 13 Mart 2019 ve Kabul Tarihi 31 Mart 2019)

(DOI: 10.31590/ejosat.545139)

\begin{abstract}
ATIF/REFERENCE: Akçimen, C. \& Antmen, F. (2019). Kısıtlar Teorisinde Kapasite Kısııı ve Bir Üretim İşletmesinde Uygulamas1. Avrupa Bilim ve Teknoloji Dergisi, (15), 618-626.

$\ddot{O} \mathbf{z}$

İşletmelerin karlılık hedeflerine ulaşabilmeleri için müşterilerinin taleplerini mümkün olduğunca hızlı, zamanında ve istenilen miktarlarda karşılamaları gerekmektedir. Aksi halde müşteri ve prestij kaybı yaşanabilir. Müşterilere zamanında, istenen miktarda ürün verebilmenin yollarından biri kapasitenin (iş gücü, makine, çalışma saati vb.) yeterli olabilmesidir. Bu çalışmada Kısıtlar Teorisi üzerinde durulmuş ve çalışma, kapasite kısıtı üzerine temellendirilmiş̧ir. Kısıtlar Teorisi, işletmenin hedeflerine ulaşmasına engel olan problemleri belirlemeyi ve bu problemleri ortadan kaldırmayı hedefler. Aynı zamanda, bu problemler için gerekli olan değişiklik veya düzenlemelerin uygulanmasını sağlayan bir yönetim disiplinidir. İşletmeler kısıtları tespit edip yöneterek üretim süreçlerini daha akıcı hale getirebilirler. Kısıtların yönetilmesi işletme içindeki darboğazların önüne geçilmesini sağlar. Bu sayede hem müşterilere zamanında talep miktarı kadar ürün sağlanır hem de kısıtlardan kaynaklı boşta bekleme süresi, stok maliyetleri vb. maliyetler azalır. Böylece firmanın kâr marjı yükselir ve pazar payı artar. Çalışmada Kısıtlar Teorisinin önemi üzerine durulmuş ve kapasite kısıtı üzerine bir uygulama gerçekleştirilmiştir. Uygulama yapılan imalat işletmesinin kârını arttırabilmek için Kısıtlar Teorisinin kullanılmasının yarattığı fayda gösterilmeye çalışılmıştır.
\end{abstract}

Anahtar Kelimeler: Kısıtlar Teorisi, Kapasite Kısıtı, Katkı Payı, Optimum Kâr

\section{Capacity Constraint in Theory of Constraint and its Application in a Production Enterprise}

\begin{abstract}
The profitability of the enterprises of the demands of their customers as fast as possible in order to help achieve their goals on time and must meet the required quantities. Otherwise customer and prestige loses can be occurred. One of the ways to give the product to customers on time might be enough by the desired amount of capacity (manpower, machinery, working hours, etc.). In this study, we focused on the theory of constraints based on capacity constraint. Theory of constraints and identifying problems that kept it from achieving the objectives of the enterprise and aims to eliminate these problems. At the same time, management changes that are required for these problems that provides for the enforcement of discipline or regulations. Enterprises can make their production processes more streamlined by managing and detecting these constraints. Managing constraints provides a chance to avoid bottlenecks managing constraints in business. In this way, both constraints will crop up that is both timely to the customers the requested amount sourced from standby idle time, inventory costs, etc. costs are reduced. Thus, the share of the firm's profit margin rises and marketshare increases. The study focuses on the importance of the theory of constraints, and conducted a survey on the capacity constraint.
\end{abstract}

Keywords: Theory of Constraints, Capacity Constraints, Contribution, Optimum Profit.

*Sorumlu Yazar: Çukurova Üniversitesi, Mühendislik Fakültesi, Endüstri Mühendisliği Bölümü, Adana, Türkiye cem.akcimen@gmail.com 


\section{Giriş}

Kısıtlar Teorisi, 1980'lerin başından itibaren bir dizi kitap ve makale şeklinde Eliyahu Goldratt tarafından geliştirilen, kısıtların yönetilmesi ve senkronize üretim yoluyla sürekli gelişmeyi hedef alan bir yönetim felsefesidir. Teori örgütün belirlediği hedeflere ulaşabilmesi için, yönetimin bazı kısıtlar üzerinde yoğunlaşması gerektiğini savunmaktadır (Büyükyılmaz ve Gürkan, 2009). Kısıtlar Teorisi'nin iki bakış açısı vardır. Bunlardan birincisi, işletmenin bir sistem olarak tanımlanması, ikincisi ise sürekli yenilenen gelişme sürecidir. Kısıtlar Teorisi’nde sistem, bir zincire benzetilmektedir. Zincirin gücü ise, en zayıf halkaya bağlıdır. Bu nedenle işletmenin performansını, bunun sonucuna bağlı olarak da elde edilecek işletme başarısını artırmak için kısıt, en etkin bir şekilde yönetilmelidir (Şahin, 2012).Sistemde bir noktada ortaya çıkan kısıt tüm sistemin etkinliğini bozacak, bu da firmanın kârlılığını olumsuz etkileyecektir. Bu nedenle firma yönetiminin, sistemde ortaya çıkan kısıtları belirleyip ortadan kaldırmaya çalışması gerekmektedir. Kısıtların belirlenip giderilmesi ile firmaların üretim süreci daha akıcı hale gelecek, kısıtlardan dolayı ortaya çıkan maliyetler azalacaktır. Bunların sonucu olarak da ürün kalitesi, firma kârlılı̆ğ ve verimliliğgi artacak, bu da firmaların rekabet ortamında müşteri ihtiyaçlarını kaliteli ürünlerle daha çabuk karşılamasıyla rekabet avantajını arttıracaktır (Küçüksavaş ve ark., 2005).Zaman ilerledikçe, teknoloji geliştikçe müşteri ihtiyaç ve beklentileri artmakta dolayısı ile yöneticilerin de istekleri değişmektedir. Bu isteklerin karşılanması firmanın ayakta kalabilmesi yani rekabet gücünü yükseltebilmesi ve piyasada belirleyici olması açısından büyük öneme sahiptir. Temel amaç müşteri memnuniyetini sağlamak ve firma karlılığını artırmaktır. Bu sürecin doğru işleyebilmesi ve istenen sonuçları verebilmesi için müşteri memnuniyetin en ekonomik şekilde karşılanması gerekmektedir. İşte bu noktada da Kısıtlar Teorisi yöneticilere karar verme aşamasında yardımcı olan bir yaklaşımdır. Kısıtların tespit edilmesiyle sorunların nereden kaynaklandığı veya başka bir deyişle darboğazın nerede olduğu görülür. Böylelikle yönetimin asıl odaklanacağı sorun belli olur. Sorunu çözmeye yönelik yöntemler, düzeltmeler, iyileştirmeler veya farklı sorun çözme teknikleri uygulanır ve daha sonra firmanın hedeflerine ulaşması sağlanmış olur. Piyasadaki bir imalat işletmesi için ürün yaşam döngülerinin uzatılması ve rekabet gücünün korunması için kısıtlar teorisinin sürekliliği önem arz etmektedir. Bu çalışmada kısıtlar teorisinden teorik olarak bahsedilmiş, daha önce yapılan çalışılmalara değinilmiş, bir uygulamayla kapasite kısıtının iyileştirilmesi ile elde edilen sonuçlar incelenmiş ve kısıtlı katkı payı oranının işletmeler açısından etkisi gösterilmiştir. Çalışmanın geri kalan kısmı şu şekilde düzenlenmiştir: 2. kısımda kısıtlar teorisi ve dahilindeki kavramlardan bahsedilmiş, 3. kısımda konu ile ilgili literatür taraması yapılarak çalışmaların kısa bir özeti sunulmuştur, 4. Kısımda uygulama yapılan işletmede kısıtlar teorisinin faydası gösterilmiştir, 5. kısımda genel değerlendirme yapılarak sonuç ifade edilmiştir.

\section{Kısıtlar Teorisi}

Kısıtlar teorisi sistem geliştirmeye odaklanır. Sistem birbirine bağlı bir dizi süreçler olarak tanımlanır ve bu sistem bir zincire benzetilebilir. Zincir aynı hedef doğrultusunda beraber çalışan ve birbirine bağlı bir gruptur. Kısıt ise bu zincirde zayıf bir bağı temsil eder. Tüm zincirin performansı zayıf bağın kuvvetiyle sınırlıdır. Kısıtlar teorisi süreç üzerine yoğunlaşır (Nave, 2002).

Kısıtlar Teorisi belirli adımlardan oluşmaktadır ve bu adımlar aşağıda listelenmiştir (Geri ve Ahituv, 2008) :

1. Sistemin amacı belirlenir.

2. Performans ölçüleri belirlenir.

3. Sistemin kısitları belirlenir.

4. Kısıtı ortadan kaldırılma yollarına karar verilir.

5. En uygun yol (müşteri istekleri doğrultusunda maliyeti en az etkileyecek, karı arttıracak) seçilir.

6. Kısıt ortadan kaldırılır veya kısıtta iyileştirmeler, düzeltmeler yapılır.

7. Üçüncü aşamadan başlanarak döngü sürekli devam ettirilir.

Kısıtlar Teorisinin esas amacı, eş zamanlı üretim yoluyla sürekli iyileştirme sürecini işletmede kurmaktır. Eş zamanlı üretim kavramı, pazardan gelen taleplere cevap verebilmek için verimli kaynaklar aracılığıyla malzemelerin hareket ettirilmesini sağlayan sistematik yöntem olarak tanımlanır. Kısıtlar Teorisi yaklaşımının yapmak istediği öncelikle kaynak kısıtları tespit etmek ve onları yönetmek için programlar yapmaktır (Erol, 2008). Kısıtlar teorisinin amacı firmanın karlılık hedeflerine engel teşkil edebilecek kısıtların yönetimini sağlamaktır çünkü her firma işleyişi esnasında en az bir kısıtla karşılaşmaktadır. Üretimin akıcı hale gelebilmesi için kısıtların tespit edilmesi ve ortadan kaldırılması gerekmektedir. Bu sayede üretim akıcılık kazanarak hem verimlilikte hem de karlılıkta artış meydana gelmektedir (Tiryakigil, 2011). Kısıtlar Teorisi'nin temel ilkeleri aşağıdaki gibi özetlenebilir (Akman ve Özcan, 2008):

1. Tüm sistemler ve süreçler birbirine bağlidırlar ve zincire benzerler.

2. Her sistemde en az bir kısıt mevcuttur. Bu kısıt sistemdeki darboğaz ya da en zayıf halkadır.

3. Zincirin en zayıf halkasının güçlendirilmesi, yani bu kısıtın iyileştirilmesi sistemin tamamında performans artışı sağlar.

4. Kısıtlar türlerine göre politika, planlama, davranış, kapasite ve pazar kısıtları şeklinde sınıflandırılabilir.

5. Kısıt olmayan bir kaynak veya süreçte yapılacak herhangi bir iyileştirme sistemin toplam performansını etkilemeyecektir. Bu nedenle gereksizdir.

Kısıtlar teorisi sisteminde oluşan kısıt türleri aşağıda şekil 1'de gösterilmiştir.

Şekil 1'de gösterilen kısıt türlerini kısaca açıklayacak olursak;

1.Pazar Kısıtları: Pazar talebinde meydana gelen dengesizlik sonucu işletme kapasitesinde ortaya çıkan kısıt türüdür.

2.Politik Kısıtlar: Yöneticilerin yeteneksizlikleri sonucu karşılarına çıkan firsatları değerlendirememesi sonucu ortaya çıkan kısıt türüdür.

3.Hammadde Kısıtları: Dış bir kaynak olan hammaddenin kıt olması sonucu ortaya çıkan kısıt türüdür.

e-ISSN: 2148-2683 


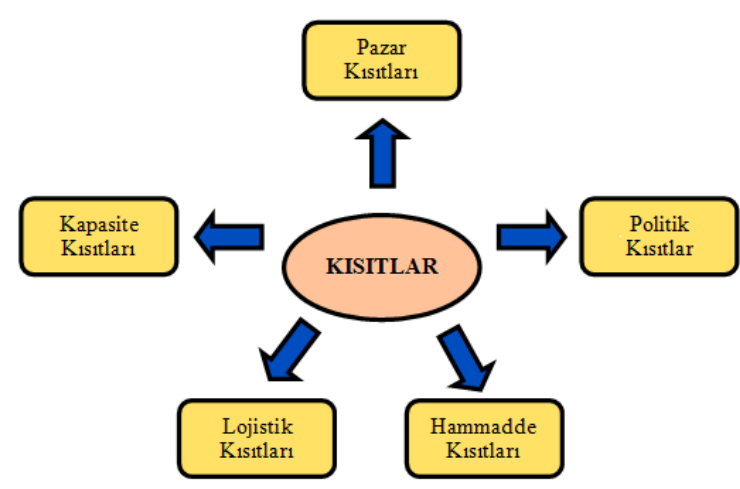

Şekil 1: Kısıt Türleri (Karagün ve Sözen, 2017)

4.Lojistik Kısıtlar: İşletme içinde uygulanan prosedürlerin işletme faaliyetlerini sınırlaması sonucu ortaya çıkan kısıt türüdür. 5.Kapasite Kısıtları: : İşletme kaynaklarının pazar talebi karşısında yetersiz kalması sonucu ortaya çıkan kısıt türüdür (Büyükyılmaz ve Gürkan, 2009).

\subsection{Kapasite kavramı ve kapasite kısıtı}

Kapasite konusu, 1920 ’lerden sonra işletmecilikte faaliyete geçirilen ve günümüzde önemle üzerinde durulan konulardan biridir. Çünkü "kapasite" kavramından, üretilecek ürünün nicelik, teslim zamanı ile kazanç ya da sosyal gereksinmenin karşılanmasındaki düzeyi anlaş1lır (Demir ve Gümüşoğlu, 1998).

Üretim sürecindeki kısıtlar düşünüldüğünde, ilk akla gelen kısıtlardan birisi kapasite kısıtıdır. Çünkü hemen her firmada üretim sürecinin akışını olumsuz olarak etkileyecek, kapasitesi dar olan belirli kaynaklar bulunmaktadır. İşletmeler, stratejik misyonlarıyla tutarlı bir şekilde, mevcut ve gelecekteki talebi zaman ve miktar cinsinden karşılamak için yeterli kapasiteye ihtiyaç duyarlar. Kapasite, işletmenin üretim yeteneğinin bir ölçüsüdür ve "bir işletmede belli bir dönemde ulaşılabilecek çıktı hacmidir." ya da "belli bir dönemde kullanılan üretim faktörleridir.” şeklinde tanımlanabilir (Üreten 1999).

Kapasite kararları, kullanılacak teknolojiye ilişkin stratejik kararla da yakından ilgilidir ve büyük sermaye yatırımları gerektirir. İşletmelerde yatırım üzerinden getirinin önemli bir kriter olması nedeniyle, kapasite planlama kararlarının yol açtığı maliyetler ve sağlayacağı getiriler dikkatli bir şekilde değerlendirilmelidir. İşletme yöneticileri birçok nedenden dolayı kapasite kavramıyla yakından ilgilenirler. Bu nedenlerde ilki, mevcut ve gelecekteki talebi karşılamak üzere kapasite planlamasına ihtiyaç duyarlar. İkinci olarak, mevcut makinelerin bakım maliyetleri ve iş akışı da üretim kapasitesiyle yakından ilgili olup, bu durum üretim verimliliğini de etkilemektedir. Üçüncü olarak, karlı bir yatırım yapabilmek için önceden üretim kapasitesinin bilinmesi gerekir. İşletme yöneticileri rasyonel bir yatırım gerçekleştirebilmek ve yatırım maliyetleriyle yatırım gelirlerini dengeleyebilmek için kapasite seçimini dikkatli bir şekilde yapmalıdırlar (Bulut, 2004).

Belirli bir zaman aralığındaki üretim miktarı kapasite anlamına gelir ve eğer bu miktar müşterinin talep ettiği miktardan az ise burada bir kapasite kısıtının yani bir darboğazın varlığından söz edilebilir. Kapasite kısıtı iş gücü, makine, zaman gibi faktörlerden meydana gelebilmektedir. Bu faktörlerin talebi karşılayacak düzeye çekilmesi kapasite kısıtını ortadan kaldıracaktır. Kısııın ortadan kalkması müşteriye zamanında, istenilen miktarda ürün tesliminin yapılması anlamına gelecek ve müşteri memnuniyeti sağlayacaktır. Fakat bu durumun sağlanması belki de firma karlılığını olumlu etkilemeyecektir. Bu çalışmada gerçekleştirilen uygulamada firmanın kaynaklarında herhangi bir değişime gidilmeden yani eldeki mevcut kaynaklarla gerçekte hesaplanan ürün karmasıyla, Kısıtlar Teorisi’nin saat başına düşen katkı payı ele alınarak hesaplanan ürün karması karşılaştırılmış ve kâra olan etkileri tartışılmıştır.

\section{Literatür Taraması}

Kısıtlar Teorisi hakkında Goldratt (1984) tarafından ilk çalışmaların yapılmış olmasına rağmen Wolfgang Mewes "Machtorientierte Führungstheorie" (1963) ve Energo-Kybernetic Sistemi (1971) güç odaklı yönetim teorisi üzerine ve darboğazlar teorisi üzerine yayınları bu teorinin temellerinin 1970'lere uzandığını göstermektedir. Goldratt'ın 1984 yılı basımlı "The Goal" adlı kitabında tanıtılan bu teori için "genel bir yönetim felsefesi anlayışı" demektedir (Karagün ve Sözen, 2017).

Nave'in 2002 yılında gerçekleştirdiği çalışmada altı sigma, yalın düşünce sistemi ve kısıtlar teorisi karşılaştırılmıştır. Kısıtlar teorisine zincir benzetimi yapılmış ve kısııın bu zincirdeki bir bağı temsil ettiği düşüncesiyle zincirin toplam gücünün bu bağın kuvveti olduğu belirtilmiştir. "Bir zincirin kuvveti en zayıf halkanın kuvveti kadardır." sonucuna varılmış ve kısıtlar teorisinin beş adımı ayrı ayrı açıklanmıştır (Nave, 2002).

Küçüksavaş ve arkadaşlarının 2005 yılında yayımlanan çalışmalarında kısıtlar teorisinden teorik olarak bahsedilmiş; süreç, net kar ve yatırım karlılığı formüllerle ifade edilmiştir. Kısıtlar Teorisinin beş adımlı süreci açıklanmış ve kısıtlar teorisi üzeri bir işletmede bir uygulama gerçekleştirilmiştir. Uygulama neticesinde kısıtlar teorisi ile satışların ve toplam sürecin arttığı, yarı mamul stoklarının azaldığı ve bunların sonucu olarak da siparişlerin eksiksiz ve zamanında karşılanabildiği tespit edilmiştir (Küçüksavaş ve ark., 2005). 
Büyükyılmaz ve Gürkan (2009) çalışmalarında, kısıtlar teorisi üzerine detaylı bir analiz gerçekleştirmiştir. Bu çalışmada kısıtlar teorisi, özellikleri, işletmedeki kısıt türleri anlatılmıştır. Kısıtların yönetilmesi sürekli gelişim modeliyle gösterilmiştir. Son olarak da kısıtlar teorisinin işletmelere sağladığı faydalar ve kısıtlar teorisine yönelik eleştiriler ortaya konmuştur (Büyükyılmaz ve Gürkan, 2009).

Tiryakigil 2011 yılında yaptığı çalışmada öncelikle malzeme yönetiminin üretimdeki ve organizasyondaki yeri ve önemi üzerinde durmuştur. Kısıtlar teorisinin üretim sürecinde ele alınması ile ilgili Etapak Baskı ve Ambalaj San. Tic.A.Ş. işletmesinde bir uygulama gerçekleştirmiştir. Bu çalışma yardımıyla bir işletmenin kendi içinde bulunan kısıtlarını nasıl tespit edip aktif hale getireceği, ürün karmasını belirlerken izlemesi gereken yolu ve iyileştirmenin finansal değerler üzerinde meydana getirdiği değişimler ortaya konmaya çalışılmıştır (Tiryakigil, 2011).

2017 yılında Akman ve Özcan tarafından yapılan çalışmada kısıtlar teorisinin temel ilkelerinden ve beş aşamalı sürecinden bahsedilmiştir. Çalışma bünyesinde, 2005-2016 yılları arasında kısıtlar teorisi konusunda Türkiye'de yapılan makaleler incelenmiştir. $\mathrm{Bu}$ makalelerin Kısıtlar Teorisi felsefesini, yönetim sistemlerinin karşılaştırılmasını, düşünce süreçlerini, ürün karmasının belirlenmesini ve beş odaklanma adımının uygulamalarını açıklayan çalışmalar olduğu görülmüştür. Daha sonra bu makalelerle ilgili istatistikler değerlendirilmiştir (Akman ve Özcan, 2017).

Kaygusuz 2011 yılında kısıtların işletmenin performansını nasıl etkilediklerini incelemiş, kısıtların işletme performansı üzerindeki etkilerini göstergeler yardımıyla açıklamaya çalışmıştır. Özellikle maliyet-hacim-kar analizine odaklanmış, bir doğrusal programlama modeli oluşturarak kısıt ortamında maliyet-hacim-kar analizleri ve ilgili göstergeleri incelemiştir (Kaygusuz, 2011).

2017 yılında Karagün ve Sözen'in çalışmasında kısıtlar teorisi teorik olarak incelenmiş, kısıt türlerinden, kapasite kavramından ve çeşitlerinden bahsedilmiştir. Kısıtlı katkı payı açıklanmış ve bir uygulama ile kısıtlar teorinin kara etkisi gösterilmiştir (Karagün ve Sözen, 2017).

Şahin'in 2012 yılında yaptığı doktora çalışmasında Kısıtlar Teorisi'nin tanımları, temel kavramları ve uygulamaları ile ilgili bilgiler verilmiştir. Motivasyonla ilgili teorik bilgiler sunulmuş, bir işletmenin başarısı ile ilgili temel kavramlar açılanarak başarıyı etkileyen faktörler incelenmiştir. PVC sektöründe faaliyet gösteren bir sanayi işletmesinde, kısıtlar teorisine göre çalışanların motivasyon analizini yaparak, motivasyonun işletme başarısına etkisi araştırılmıştır. Kısıtlar Teorisi uygulaması ve gerçekleştirilen araştırma yöntemi açıklanarak, çalışma sonunda elde edilen araştırma bulguları değerlendirilmiştir (Şahin, 2012).

Bu çalışmayla, Kısıtlar Teorisi’nin saat başına düşen katkı payı ele alınarak hesaplanan ürün karmasıyla gerçekte hesaplanan katkı payına göre ürün karması karşılaştııılmış ve kârın nasıl etkilendiği incelenmiştir. Ek olarak ürün karmasının ve kârın bir optimizasyon yazılımında vereceği sonuçlar hesaplanmıştır. Böylece doğruluğu kesin bilgilere ulaşılabilmiş ve kâr açısından da daha net kararlar verilmiş̧ir.

\section{Bir İmalat İşletmesinde Kısıtlar Teorisi Üzerine Uygulama}

Uygulamanın gerçekleştirildiği imalat işletmesi metal sektöründe faaliyet göstermektedir; kaplamalı ve kaplamasız olmak üzere iki çeşit ürün üretmektedir. Bu ürünler üç adet $\mathrm{CAL}$, BAF ve TMP olarak simgelenen makinelerden geçip son ürün hallerini almaktadırlar. Uygulamanın bu işletmede yapılmasının sebebi karşılanamayan taleplerin olması ve bu nedenle işletmenin mevcut üretim kapasitesinde uyguladığı ürün karmasının en karlı yöntem olup olmadığını araştırmaktadır. Uygulamada bu makinelerin kapasite kullanım oranları üzerine inceleme yapılmış ve karda kısıtlar teorisiyle ne gibi bir değişim olacağı ortaya konmuştur. Her iki ürün çeşiti için geçerli olan üretim süreci aşağıda şekil 2'de gösterilmektedir.

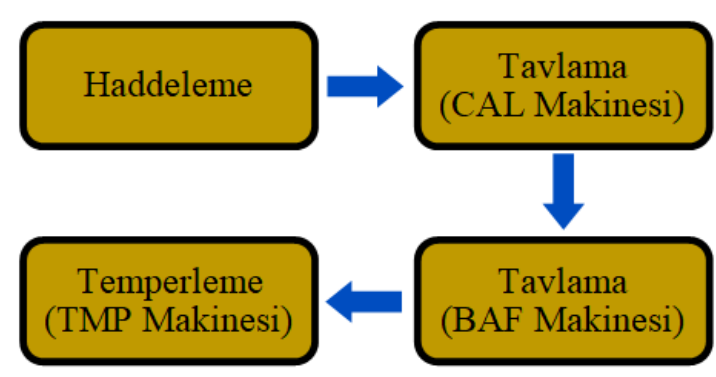

Şekil 2: İşletme Akış Şeması

Ürün çeşitlerine ait üretim sürecinde öncelikle işletmeye sıcak bobin hammadde olarak gelir. Haddeleme makinesinde hammadde istenilen kalınlığa göre haddelenerek inceltilir. Daha sonra ürün üzerinde oluşan tufaller temizlenir. CAL ve BAF makinelerinde ürünler tavlanır ve TMP makinesinde temperleme işleminden sonra ürün son halini alır. Sistemde tavlama veya temperleme aşamalarında kapasite konusunda sıkıntı olduğu tahmin edilmiştir. Bu aşamalarda hizmet veren CAL, BAF ve TMP makinelerinin kapasite kullanım oranları incelemeye alınmıştır. Makinelerin kapasite kullanım oranlarının hesaplanabilmesi için gerekli olan verilerden birisi ürünlerin makinelerdeki birim işlem sürelerini hesaplamaktır. İşletmedeki makineler 24 saat çalışmaktadır. Aşağıda Tablo 1'de ürünlerin 24 saat içinde saatlik ortalama üretim miktarları verilmiştir. Tablo 1'de makineler "M." , ürün birimleri "br." ile kısaltılarak gösterilmiştir. 
Tablo 1: Makinelerde günlük ortalama çıkan kaplamalı ve kaplamasız ürün miktarı

\begin{tabular}{|c|c|c|c|c|c|c|}
\hline \multirow[t]{2}{*}{ Saat } & \multicolumn{3}{|c|}{ Kaplamalı Ürün } & \multicolumn{3}{|c|}{ Kaplamasız Ürün } \\
\hline & CAL M. & BAF M. & TMP M. & CAL M. & BAF M. & TMP M. \\
\hline 1. sa & $30 \mathrm{br}$. & & 38 br. & 27 br. & - & 58 br. \\
\hline 2. sa & $30 \mathrm{br}$. & 57 br. & 38 br. & $27 \mathrm{br}$. & - & 58 br. \\
\hline 3. sa & $30 \mathrm{br}$. & - & 38 br. & 27 br. & 102 br. & 58 br. \\
\hline 4. sa & $30 \mathrm{br}$. & 70 br. & 38 br. & 27 br. & 93 br. & 58 br. \\
\hline 5. sa & $30 \mathrm{br}$. & - & 38 br. & 27 br. & - & 58 br. \\
\hline 6. sa & $30 \mathrm{br}$. & - & 38 br. & $27 \mathrm{br}$. & - & 58 br. \\
\hline 7. sa & $30 \mathrm{br}$. & - & 38 br. & $27 \mathrm{br}$. & - & 58 br. \\
\hline 8. sa & $30 \mathrm{br}$. & - & 38 br. & $27 \mathrm{br}$. & 89 br. & 58 br. \\
\hline 9. sa & $30 \mathrm{br}$. & 70 br. & 38 br. & 27 br. & - & 58 br. \\
\hline 10. sa & $30 \mathrm{br}$. & - & 38 br. & $27 \mathrm{br}$. & - & 58 br. \\
\hline 11. sa & $30 \mathrm{br}$. & 62 br. & 38 br. & 27 br. & - & 58 br. \\
\hline 12. sa & $30 \mathrm{br}$. & - & 38 br. & 27 br. & 94 br. & 58 br. \\
\hline 13. sa & $30 \mathrm{br}$. & - & 38 br. & 27 br. & - & 58 br. \\
\hline 14. sa & $30 \mathrm{br}$. & - & 38 br. & 27 br. & - & 58 br. \\
\hline 15. sa & $30 \mathrm{br}$. & - & 38 br. & 27 br. & 99 br. & 58 br. \\
\hline 16. sa & $30 \mathrm{br}$. & - & 38 br. & 27 br. & - & 58 br. \\
\hline 17. sa & 30 br. & - & 38 br. & 27 br. & - & 58 br. \\
\hline 18. sa & $30 \mathrm{br}$. & - & 38 br. & 27 br. & - & 58 br. \\
\hline 19. sa & $30 \mathrm{br}$. & - & 38 br. & 27 br. & - & 58 br. \\
\hline 20. sa & $30 \mathrm{br}$. & - & 38 br. & 27 br. & - & 58 br. \\
\hline 21. sa & $30 \mathrm{br}$. & 67 br. & 38 br. & 27 br. & $108 \mathrm{br}$. & 58 br. \\
\hline 22. sa & $30 \mathrm{br}$. & - & 38 br. & 27 br. & - & 58 br. \\
\hline 23. sa & $30 \mathrm{br}$. & - & 38 br. & 27 br. & - & 58 br. \\
\hline 24. sa & $30 \mathrm{br}$. & 67 br. & 38 br. & 27 br. & - & 58 br. \\
\hline \multicolumn{7}{|c|}{ TOPLAM } \\
\hline 24 saat(1gün) & 720 br. & 393 br. & 912 br. & 648 br. & 585 br. & 1392 br. \\
\hline
\end{tabular}

Her bir ürün için makinelerdeki ortalama toplam üretim miktarları tablo 1'de görülmektedir. Bu veriler doğrultusunda makinelerin birim işleme süreleri hesaplanmış ve Tablo 2'de bu süreler verilmiştir. Ürünlere ait aylık talep miktarları Tablo 2 ve 3 'de belirtilmiştir.

Tablo 2: Kaplamalı ürüne ait makinelerin birim işlem süreleri

\begin{tabular}{|l|ll|}
\hline \multicolumn{2}{|l|}{ KAPLAMALI ÜRÜN } \\
\hline Aylık Talep & $7.500 \mathrm{br} / \mathrm{ay}$ \\
\hline Makinelerin Birim İşlem Süresi \\
\hline 1.CAL & $0,033 \mathrm{sa} / \mathrm{br}$ & (24 saat/720 birim) \\
\hline 2.BAF & $0,061 \mathrm{sa} / \mathrm{br}$ & (24 saat/393 birim) \\
\hline 3.TMP & $0,026 \mathrm{sa} / \mathrm{br}$ & (24 saat/912 birim) \\
\hline
\end{tabular}

CAL makinesinde günlük ortalama 720 birim kaplamalı ürün üretilmektedir. Daha önce belirtildiği üzere makinenin günlük çalışma süresi 24 saattir. 720 birim üretim 24 saate bölünerek kaplamalı ürüne ait CAL makinesinin birim işlem süresi hesaplanmıştır. Aynı şekilde kaplamasız ürün için de ilgili makinedeki günlük ortalama üretim miktarı aynı makineye ait günlük çalışma saatine bölünerek ürünlere ait birim işlem süreleri hesaplanmıştır.

Tablo 3: Kaplamasız ürüne ait makinelerin birim işleme süreleri

\begin{tabular}{|l|lr|}
\hline \multicolumn{3}{|l|}{ KAPLAMASIZ ÜRÜN } \\
\hline Aylk Talep & $5.000 \mathrm{br} / \mathrm{ay}$ & \\
\hline Makinelerin Birim İșlem Süresi & \\
\hline 1.CAL & $0,037 \mathrm{sa} / \mathrm{br}$ & $(24 \mathrm{saat} / 648 \mathrm{birim})$ \\
\hline 2.BAF & $0,041 \mathrm{sa} / \mathrm{br}$ & $(24 \mathrm{saat} / 585 \mathrm{birim})$ \\
\hline 3.TMP & $0,017 \mathrm{sa} / \mathrm{br}$ & $(24 \mathrm{saat} / 1392 \mathrm{birim})$ \\
\hline
\end{tabular}

Uygulama yapılan üretim işletmesinin kaplamalı ve kaplamasız ürünlerine gelen taleplerin hepsinin karşılanıp satılması için işletmenin aylık kapasitesinin yeterli olup olmadığının bilinmesi gerekmektedir. Kapasite kısıtı var olan makine veya makinelerin 
tespitinden sonra ürün karmaları hesaplanıp kar kıyaslamaları yapılacaktır. İşletmenin kısıt tespitine ilişsin veriler aşağıdaki Tablo 4 ile verilmiştir. Tablo 4'de kaplamalı ürün "T", kaplamasız ürün "S" ile ifade edilmiştir.

Tablo 4: Makinelere Illişkin Kapasite Kullanım Oranları

\begin{tabular}{|c|c|c|c|c|c|c|}
\hline 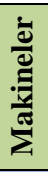 & Ürünler & $\begin{array}{l}\text { Birim } \\
\text { İşlem } \\
\text { Süresi } \\
\text { (1) }\end{array}$ & $\begin{array}{l}\text { Talep } \\
\text { Miktarı } \\
\text { (2) }\end{array}$ & $\begin{array}{l}\text { Aylik } \\
\text { Gerekli } \\
\text { Kapasite } \\
\text { (3)=(1)x } \\
\text { (2) } \\
\end{array}$ & $\begin{array}{l}\text { Toplam } \\
\text { (Aylık) } \\
\text { Kapasite } \\
\text { (4)=24 saat } \\
\text { x 20 gün }\end{array}$ & $\begin{array}{l}\text { Kapasite } \\
\text { Kullanım } \\
\text { Oranı } \\
=(3) /(4) x \\
100\end{array}$ \\
\hline & $\mathbf{T}$ & $\begin{array}{l}0,033 \\
\text { sa/br }\end{array}$ & $\begin{array}{l}7.500 \\
\text { br/ay }\end{array}$ & $\begin{array}{l}247,5 \\
\text { sa/ay }\end{array}$ & \multirow[b]{2}{*}{480 sa/ay } & \multirow[b]{2}{*}{$\% 90,1$} \\
\hline 远 & $\mathbf{S}$ & $\begin{array}{l}0,037 \\
\mathrm{sa} / \mathrm{br}\end{array}$ & $\begin{array}{l}5.000 \\
\text { br/ay }\end{array}$ & $\begin{array}{l}185 \\
\text { sa/ay }\end{array}$ & & \\
\hline \multicolumn{4}{|c|}{$\operatorname{Toplam}(3)=$} & $\begin{array}{l}432,5 \\
\text { sa/ay }\end{array}$ & & \\
\hline \multirow{2}{*}{$\sum_{0}^{1}$} & $\mathbf{T}$ & $\begin{array}{l}0,061 \\
\mathrm{sa} / \mathrm{br}\end{array}$ & $\begin{array}{l}7.500 \\
\text { br/ay }\end{array}$ & $\begin{array}{l}457,5 \\
\text { sa/ay }\end{array}$ & \multirow{2}{*}{480 sa/ay } & \multirow{2}{*}{$\% 138$} \\
\hline & $\mathbf{S}$ & $\begin{array}{l}0,041 \\
\mathrm{sa} / \mathrm{br}\end{array}$ & $\begin{array}{l}5.000 \\
\text { br/ay }\end{array}$ & $\begin{array}{l}205 \\
\text { sa/ay }\end{array}$ & & \\
\hline \multicolumn{4}{|c|}{ Toplam $(3)=$} & $\begin{array}{l}662,5 \\
\text { sa/ay }\end{array}$ & & \\
\hline & $\mathbf{T}$ & $\begin{array}{l}0,026 \\
\mathrm{sa} / \mathrm{br}\end{array}$ & $\begin{array}{l}7.500 \\
\text { br/ay }\end{array}$ & $\begin{array}{l}195 \\
\text { sa/ay }\end{array}$ & \multirow{2}{*}{480 sa/ay } & \multirow{2}{*}{$\% 58,3$} \\
\hline$E$ & $\mathbf{S}$ & $\begin{array}{l}0,017 \\
\mathrm{sa} / \mathrm{br}\end{array}$ & $\begin{array}{l}5.000 \\
\text { br/ay }\end{array}$ & $\begin{array}{l}85 \\
\text { sa/ay }\end{array}$ & & \\
\hline \multicolumn{4}{|c|}{$\operatorname{Toplam}(3)=$} & $\begin{array}{l}280 \\
\text { sa/ay }\end{array}$ & & \\
\hline
\end{tabular}

Tablo 2 ve Tablo 3 'te aylık gerekli kapasiteyi bulmak için ürünlere ait hesaplanan işlem süreleri talep miktarlarıyla çarpılmıştır. CAL makinesi için, her bir ürün tipi için birim işlem süresi talep miktarı ile çarpılarak ilgili ürünün aylık gerekli kapasitesi hesaplanmıştır. Bu iki değer toplanarak CAL makinesi için aylık toplam gerekli kapasite elde edilmiştir. Aylık kapasite Tablo 4'de belirtildiği üzere günlük 24 saat ve aylık 20 gün çalışma ile 480 sa/ay'dır. CAL makinesi için aylık gereken kapasite hesaplaması ile elde edilen 432,5 sa/ay kapasitesi, toplam(aylık) kapasite hesaplaması ile elde edilen 480 sa/ay kapasitesine bölünüp 100 ile çarpılarak bu makineye ait kapasite kullanım oranı elde edilir. Makineler tam kapasitelerinin üzerinde çalıştırılamaz yani makinelere ait kapasite kullanım oranının \%100 (tam kapasite)'ü aşmaması gerekmektedir. Bu oranı aşması kısııın yani darboğazın olduğunu göstermektedir. CAL makinesine ait kapasite kullanım oranının \%90,1 olması bu makineye ait bir darboğaz olmadığı anlamına gelmektedir. Diğer makinelere ait kapasite kulanım oranları da bu şekilde hesaplanmaktadır.

TMP makinesi kapasitesinin \%58,3 'lük kısmını kullanacağı için sistemde herhangi bir sıkıntıya yol açmayacak yani darboğaz oluşturmayacaktır. BAF makinesi bu talep karşısında kapasitesinin teorik olarak \%138'ini kullanmaktadır. Bu yüzdenin gerçekleşmesi mümkün değildir ve bu işletmede bir darboğazın olduğu anlamına gelmektedir. Dolayısıyla talep edilen ürünlerin tamamı karşılanamayacaktır. Darboğazın olduğu BAF makinesi ilerleyen aşamaların belirleyici unsuru olmuştur. Kısıtlar teorisinin BAF makinesine ilişkin veriler esas alınarak uygulanması belirlenmiş̧ir.

Kaplamalı ve kaplaması ürünlerin hangisine öncelik verileceği ile ilgili olarak işletme, katkı payını esas almaktadır. Katkı payı yüksek olan ürünün üretilebileceği kadar miktar üretilip geriye kalan kapasite kadar diğer ürün üretilmektedir. Ancak Kısıtlar Teorisi’ne göre esas alınan şey, katkı payının birim işlem süresine bölünerek elde edilen sonuçta yüksek değere sahip olan ürüne üretim önceliği verilmesidir. Ürünlere ait bilgiler Tablo 5'de verilmiş̧ir. 
Tablo 5: Ürünlere İlişkin Veriler

\begin{tabular}{|l|c|c|}
\hline & Kaplamalı Ürün & Kaplamasız Ürün \\
\hline Satış Fiyatı & $855 \$ / \mathrm{br}$ & $640 \$ / \mathrm{br}$ \\
\hline Değişken Maliyet & $585 \$ / \mathrm{br}$ & $550 \$ / \mathrm{br}$ \\
\hline Katk1 Payı(Satış F.-Değişken M.) & $270 \$ / \mathrm{br}$ & $190 \$ / \mathrm{br}$ \\
\hline Talep Miktarı & $7500 \mathrm{br}$ & $\mathbf{2 .}$ \\
\hline Katkı payına göre üretim önceliği & $\mathbf{1 .}$ & $0,041 \mathrm{sa} / \mathrm{br}$ \\
\hline Birim İşlem Süresi & $0,061 \mathrm{sa} / \mathrm{br}$ & 4634,1 \\
\hline $\begin{array}{l}\text { Saat Başına Düşen Katkı Payı } \\
\text { (Katkı Payı/Birim işlem süresi) }\end{array}$ & $4426,2 \$ / \mathrm{sa}$ & $\mathbf{1 .}$ \\
\hline $\begin{array}{l}\text { Saat başına düş̧en katkı payına göre } \\
\text { üretim önceliği }\end{array}$ & $\mathbf{2 .}$ & \\
\hline
\end{tabular}

Tablo 5’te görüldüğü üzere firmanın uyguladığ1 politikaya göre katkı payına göre üretim önceliği ile Kısıtlar Teorisine göre üretim önceliği birbirinden farklıdır. Bu yüzden iki yönteme göre hesaplamalar yapılıp kâr miktarlarına bağlı olarak yorumlar yapılacaktır. Öncelikle belirlenen üretim önceliklerine göre ürün miktarları aşağıda Tablo 6'da verilen şekilde hesaplanmaktadır.

Tablo 6: Üretim Önceliğine Göre Üretim Miktarı Hesaplanışı

\begin{tabular}{|c|c|c|c|c|c|}
\hline 嶽 & Ürünler & $\begin{array}{c}\text { Birim İșlem } \\
\text { Süresi (1) }\end{array}$ & $\begin{array}{c}\text { Üretim } \\
\text { Miktarı (2) }\end{array}$ & $\begin{array}{c}\text { Gereken } \\
\text { Kapasite } \\
(3)=(1) \mathbf{x}(2)\end{array}$ & $\begin{array}{c}\text { Toplam } \\
\text { Kapasite }\end{array}$ \\
\hline \multicolumn{6}{|c|}{ Katkı Payına Göre Üretim Miktarı } \\
\hline 5 & Kaplamalı & $0,061 \mathrm{sa} / \mathrm{br}$ & 7.500 br/ay & $457,5 \mathrm{sa} / \mathrm{ay}$ & \multirow{2}{*}{480 sa/ay } \\
\hline 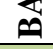 & Kaplamasız & $0,041 \mathrm{sa} / \mathrm{br}$ & 548 br/ay & 22,5 sa/ay & \\
\hline \multicolumn{6}{|c|}{ Saat Başına Düşen Katkı Payına Göre Üretim Miktarı } \\
\hline \multirow{2}{*}{$\sum^{5}$} & Kaplamalı & $0,061 \mathrm{sa} / \mathrm{br}$ & 4.508 br/ay & 275 sa/ay & \multirow{2}{*}{$480 \mathrm{sa} / \mathrm{ay}$} \\
\hline & Kaplamasız & $0,041 \mathrm{sa} / \mathrm{br}$ & $5.000 \mathrm{br} / \mathrm{ay}$ & $205 \mathrm{sa} / \mathrm{ay}$ & \\
\hline & & & Toplam $(3)=$ & 480 sa/ay & \\
\hline
\end{tabular}

İki yöntemde hesaplanan ürün karmalarına bakıldığında, saat başına düşen katkı payına göre üretim miktarının iki ürün için dengeli bir şekilde dağıldığı görülürken; katkı payına göre ise kaplamasız ürün için talep miktarının büyük bir oranının karşılanmadığı görülmektedir. Bu iki yönteme göre kar hesaplamaları yapılıp durum daha net görülebilecektir. Bu hesaplamalar Tablo 7'de verilmiştir.

Tablo 7: Yöntemlere Göre Kar Hesaplamalarl

\begin{tabular}{|c|c|c|}
\hline & Kaplamalı Ürün & Kaplamasız Ürün \\
\hline \multicolumn{3}{|c|}{ Katkı Payına Göre Üretim Önceliği } \\
\hline Birim Satış Fiyatı & $855 \$ / b r$ & $640 \$ / b r$ \\
\hline $\begin{array}{l}\text { Birim Değişken } \\
\text { Maliyet }\end{array}$ & $585 \$ / b r$ & $550 \$ / b r$ \\
\hline $\begin{array}{l}\text { Birim Katkı Payı } \\
\text { (Satış F.-Değişken } \\
\text { M.)(1) }\end{array}$ & $270 \$ / b r$ & $190 \$ / b r$ \\
\hline Üretim Miktarı (2) & $7.500 \mathrm{br}$ & 548 br \\
\hline $\begin{array}{l}\text { Katk1 Payı = } \\
(1) \times(2)\end{array}$ & $2.025 .000 \$$ & $104.120 \$$ \\
\hline Toplam Katkı Payı (3) & \multicolumn{2}{|l|}{$2.129 .120 \$$} \\
\hline $\begin{array}{l}\text { Toplam Sabit Maliyet } \\
\text { (4) }\end{array}$ & \multicolumn{2}{|l|}{$1.380 .000 \$$} \\
\hline $\begin{array}{l}\text { Toplam KAR = } \\
(3)-(4)\end{array}$ & \multicolumn{2}{|l|}{$749.120 \$$} \\
\hline \multicolumn{3}{|c|}{ Saat Başına Düşen Katkı Payına Göre Üretim Önceliği } \\
\hline Üretim Miktarı (5) & $4.508 \mathrm{br}$ & $5.000 \mathrm{br}$ \\
\hline
\end{tabular}




\begin{tabular}{|l|l|l|}
\hline $\begin{array}{l}\text { Katk1 Pay1 = (1) } \\
\times(5)\end{array}$ & $1.217 .160 \$$ & $950.000 \$$ \\
\hline $\begin{array}{l}\text { Toplam Katk1 Pay1 (6) } \\
\text { Toplam KAR }\end{array}$ & $2.167 .160 \$$ \\
\hline \begin{tabular}{l} 
(6) $-(4)$ \\
\hline
\end{tabular}
\end{tabular}

Tablo 7'de görüldüğü üzere Kısıtlar Teorisi'ne göre (saat başına düşen katkı payına göre) hesaplanan kâr miktarı daha yüksek sonuç vermiş ve kârda 38.040 \$ artış olduğu gözlenmiştir. Ayrıca problemin bir optimizasyon yazılımında vereceği sonuçlar da incelenmek istenmiş̧tir. Bu sebeple problem optimizasyon yazılımında aşağıdaki kısıtlarla formüle edilmiştir;

\section{Karar Değişkenleri}

T: Kaplamalı ürün üretim miktarı

$S:$ Kaplamasız ürün üretim miktarı

Amaç Fonksiyonu $=\operatorname{MAX}((270 * T)+(190 * S)-1380000$

\section{Kısıtlar}

$(0.033 * T)+(0.037 * S) \leq 480$

$(0.061 * T)+(0.041 * S) \leq 480$

$(0.026 * T)+(0.017 * S) \leq 480$

$T \leq 7500$

$S \leq 5000$

$T \geq 0$

$S \geq 0$

Belirtildiği üzere amaç fonksiyonunda $\mathrm{T}$ ve $\mathrm{S}$ sembolleri sırasıyla kaplamalı ve kaplamasız ürünlerin üretilmesi için gereken miktarı yani kârı maksimum yapacak üretim miktarını belirtmektedir. Denklem (1) ile ifade edilen amaç fonksiyonu, ilgili ürünün üretim miktarı ile o ürünün birim katkı payı çarpımlarının toplamlarından, toplam sabit maliyetin çıkartılması ile elde edilmiştir.

Denklem (2), CAL makinesine ait kısıt ifade etmektedir. Bu makine için kaplamalı ürüne ait birim işlem süresi (0.033) ile kaplamalı ürünün üretim miktarı çarpılır. Aynı şekilde kaplamasız ürünün birim işlem süresi (0.037) ile kaplamasız ürünün üretim miktarı çarpılır. Çarpımlardan elde edilen sonuçların toplamı makinenin aylık çalışma süresi yani kapasitesinden (480 saat) küçük veya eşit olması gerekmektedir. Çünkü bu çalışma süresinin üstüne çıkılması talep edilen miktarın tamamının karşılanmaması anlamina gelmektedir.

Denklem (3), BAF makinesine ait kısıt ifade etmektedir. Bu makine için kaplamalı ürüne ait birim işlem süresi (0.061) ile kaplamalı ürünün üretim miktarı çarpılır. Aynı şekilde kaplamasız ürünün birim işlem süresi (0.041) ile kaplamasız ürünün üretim miktarı çarpılır. Çarpımlardan elde edilen sonuçların toplamı makinenin aylık çalışma süresi yani kapasitesinden (480 saat) küçük veya eşit olması gerekmektedir. Çünkü bu çalışma süresinin üstüne çıkılması talep edilen miktarın tamamının karşılanmaması anlamina gelmektedir.

Denklem (4), TMP makinesine ait kısıt ifade etmektedir. Bu makine için kaplamalı ürüne ait birim işlem süresi (0.026) ile kaplamalı ürünün üretim miktarı çarpılır. Aynı şekilde kaplamasız ürünün birim işlem süresi (0.017) ile kaplamasız ürünün üretim miktarı çarpılır. Çarpımlardan elde edilen sonuçların toplamı makinenin aylık çalışma süresi yani kapasitesinden (480 saat) küçük veya eşit olması gerekmektedir. Çünkü bu çalışma süresinin üstüne çıkılması talep edilen miktarın tamamının karşılanmaması anlamina gelmektedir.

Kaplamalı ürüne ait talep kısıtı denkleminde kaplamalı ürününün üretim miktarının 7500 birimden küçük veya eşit olması gerektiği ifade edilmektedir. Aynı şekilde kaplamasız ürün için de üretim miktarının 5000 birimden küçük veya eşit olması gerektiği belirtilmektedir. Maksimum üretim miktarları talep edilen miktarlardır. Çünkü daha fazla üretim istenmemektedir. Bu sebeple kısıtlar talep miktarlarından eşit veya küçüktür. Bu optimizasyon yazılımının çıktıları kârı maksimum yapacak kaplamalı ve kaplamasız ürünlerin üretilmesi gereken miktarı ve elde edilecek maksimum kârı gösterecektir. Optimizasyon yazılımındaki çıktılar şunlardır;

Kaplamalı ürünü ifade eden $\mathrm{T}$ miktarı $=4.508$ birim

Kaplamasız ürünü ifade eden S miktarı $=5.000$ birim

Amaç fonksiyonu değeri $=787.213 \$$ 
Amaç fonksiyonunun değeri karın en yüksek olduğu değerdir. Kaplamalı ürün miktarını ifade eden T değeri ve kaplamasız ürün miktarını ifade eden S değeri ise bu karı en yüksek yapacak yani optimum üretim miktarlarını göstermektedir. Kısıtlar ve sonuçları Şekil 3'de gösterilmiş̧ir.

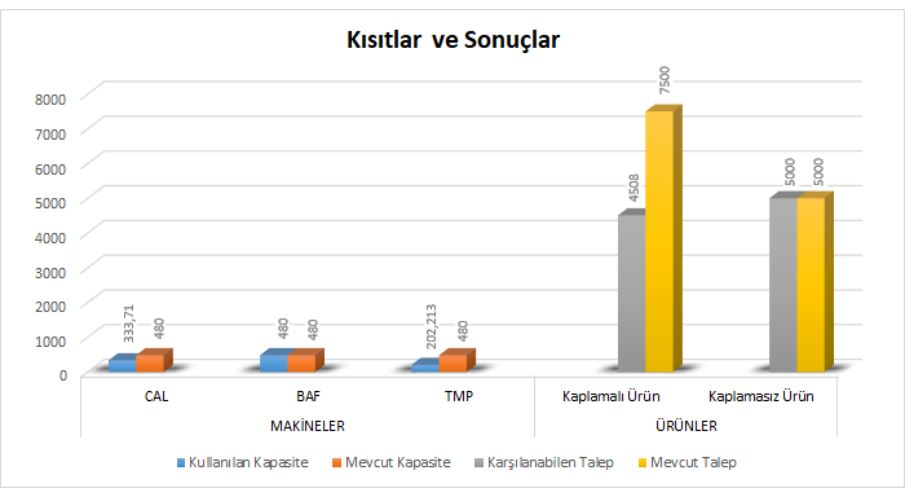

Şekil 3: Klsitlar ve Sonuçlar Sütun Grafiği

Şekil 3'de makinelere ait mevcut kapasitelerin aşılmadığı ve BAF makinesi kapasitesinin tamamının kullanıldığı görülmektedir. Optimizasyon yazılımının çıktılarına göre elde edilen sonuçlar kısıtlar teorisinin sonuçlarını doğrulamıştır. Bu da Kısıtlar Teorisi ile işletmenin kapasite kısııını kullanarak darboğazın yönetilebileceğini ve maksimum kar miktarına ulaştırabilecek üretim miktarını belirlenebileceğini göstermektedir.

\section{Sonuç}

Yapılan çalışmada Kısıtlar Teorisi üzerinde durulmuştur. Gerçekleştirilen uygulamayla kısıtlar teorisinin işletmeye olan katkısının gösterilmesi hedeflenmiştir. Firmanın mevcut kaynaklarında herhangi bir değişikliğe gidilmeden talep edilen ürünlere ait kâr getirisi en yüksek olan ürün karması oluşturulmuştur. İşletmenin geçerli işleyişinde katkı payı daha yüksek olan ürünün öncelikle üretilmesindeki ürün karması ile Kısıtlar Teorisi'ne göre elde edilen ürün karması kâr bakımından kıyaslanmıştır ve Kısıtlar Teorisi’ne göre ürün karmasında kâr getirisinin daha yüksek olduğu görülmüştür. Aynı zamanda bir optimizasyon yazılımında kısıtlara göre oluşturulan denklemler sonucunda ürün karmasının ve kâr miktarının sonuçları Kısıtlar Teorisi’nin verdiği sonuçlarla örtüşmüş̧tür. Böylece işletmelerin kapasite kısıtını kullanarak darboğazı en optimum şekilde yönetebileceği gösterilmiş ve üretim işletmelerinde yönetimin verdiği kararların kâr veya zarar üzerinde etkili olduğu sonucuna varılmıştır. Yapılan çalışmayla firmanın mevcut üretim karmasında değişikliğe gidip Kısıtlar Teorisi'ne göre oluşturulan ürün karmasının kullanılması firmanın kârlılığını, devamlılığını ve sürdürülebilirliğini arttırabileceği konusunda olumlu sonuçlar doğurmuştur.

Bundan sonra yapılacak çalışmalar için Kısıtlar Teorisi’nin kullanılabileceği alanlardan olan kapasite kısıtı dışındaki kısıtların firmaların kârını nasıl etkilediğini incelemek olabilir.

\section{Kaynakça}

Büyükyılmaz O., Gürkan S. 2009. Süreçlerde En Zayıf Halkanın Bulunması: Kısıtlar Teorisi. ZKÜ Sosyal Bilimler Dergisi 5 (9), 177195.

Şahin Ş. 2012. Kısıtlar Teorisine Göre Sanayi İşletmelerinde Çalışanların Motivasyonu ve İşletme Başarısına Etkisi: PVC Üretim İşletmesi Üzerine Bir Uygulama. Doktora tezi, T.C. Selçuk Üniversitesi Sosyal Bilimler Enstitüsü İşletme Anabilim Dalı.

Küçüksavaş N., Ünal E., Tanış V. 2005. Kısıtlar Teorisi Ve Bir Üretim İşletmesinde Uygulama. Ç.Ü. Sosyal Bilimler Dergisi 14 (2), 433-448.

Nave D. 2002. How To Compare Six Sigma, Lean and the Theory of Constraints. Quality Progress 35 (3), 73-78.

Geri N., Ahituv N. 2008. A Theory of Constraints approach to interorganizational systems implementation. Information Systems and e-Business Management 6 (4), 341-360.

Erol M. 2008. Kısıtlar Teorisi(Yaklaşımı)ve Teorisinin Stratejik Maliyet Yönteminde Kullanımı. Muhasebe ve Finansman Dergisi (39), 101-109.

Tiryakigil S. 2011. Malzeme Yönetiminde Kısıtlar Teorisi İle Maliyet Azaltımı Ve Bir Uygulama, Yüksek lisans tezi, T.C. Dokuz Eylül Üniversitesi Sosyal Bilimler Enstitüsü İşletme Anabilim Dalı.

Akman G., Özcan B 2017. Türkiye'de Kısıtlar Teorisi Ve Uygulamaları Konusunda Yapılan Çalışmalar: Literatür Taraması. Ç.Ü. Sosyal Bilimler Enstitüsü Dergisi 26 (2), 268-282.

Karagün V., Sözen M. 2017. Kısıtlar Teorisinde Kapasite Kısıtı Ve Bir Uygulama. Ekonomi ve Yönetim Araştırmaları Dergisi 6 (2), 186-199.

Demir M. H., Gümüşoğlu Ş. 1988. Üretim Yönetimi(İşlemler Yönetimi). Beta Yayınları.

Üreten S. 1999. Üretim/İşlemler Yönetimi. Ankara: Gazi Kitabevi.

Bulut Z.A. 2004. İşletmeler Açısından Kapasite Planlaması Ve Kapasite Planlamasına Etki Eden Faktörler. Mevzuat Dergisi (80)

Kaygusuz S.Y. 2011. Kısıtlar Teorisi ve Maliyet Hacim Kâr Analizi: Bir Çalışma Sayfası Modellemesi. Muhasebe ve Finansman Dergisi (52), 171-188. 